general, the action of hæm protein catalysts and lipoxidase, and finally the variable effects of aseorbic acid which, depending on the environment, acts either as pro-oxidant or as anti-oxidant.

The last paper of the meeting was that of Dr. L. A. O'Neill (Paint Research Station, Teddington) on problems of autoxidation in the paint industry. $\mathrm{He}$ pointed out that paints which depend on the ausoxidation of a drying oil or a polymeric derivative thereof, such as an oil-modified alkyd resin, are still the most widely used class. The oxidation involves the formation of $-\mathrm{C}-\mathrm{C}-$ polymers via conjugated per- oxides. Emphasis was placed on the interesting distinction between the catalytic action of cobalt compounds with oxidation spieading from the surface into the body of the medium and that of lead compounds with uniform oxidation of the bulk of the oil. Oximes are used as temporary antioxidants for sturage in containers and afterwards lost from the surface film. Mercaptans prevent the oxidation from proceeding towards degradation. The nature of 'yellowing' on prolonged ageing, which is accelerated by ammonia and other bases in the atmosphere, is not yet fully undersíood.
N. URI

\title{
AVERAGE WATER VAPOUR CONTENT OF THE AIR
}

$I^{\mathrm{N}}$ a recent memoir issued by the Meteorological Office, J. K. Bannon and L. P. Steele outline the first use of humidity observations made with radiosondes to describe, on a nearly world scale, the variation with height of the mean water vapour content of the atmosphere (Air Ministry: Meteorological Office. Geophysical Memoirs No. 102: Average Water-Vapour Content of the Air. Pp. ii +38. (M.O. 631 b). London: H.M. Stationery Office, $1960.8 s .6 d$. net). Previous work of this nature was necessarily carried out by extrapolating from surface values with empirical formulæ, deduced from mountain observations, for the rate of decrease with height.

The data, which are for the period 19511955, are presented in the form of charts for January, April, July and October of isopleths of the average weight of water vapour in decigrams above 1 square centimetre at the Earth's surface and the isobaric surfaces for $850 \mathrm{mb}$. (about $1.5 \mathrm{~km}$. height), $700 \mathrm{mb}$. (about $3 \mathrm{~km}$.) and $500 \mathrm{mb}$. (about $5.5 \mathrm{~km}$.). Surface pressure is about $1,000 \mathrm{mb}$.

The authors necessarily devote much space to a detailed discussion of the observations and of the difficult problems involved in reconciling observations made with different types of radiosonde and allowing for instrumental defects such as lag.
The most obvious feature of the charts at any one level is that water content is highest over the equatorial rain forests and India in the summer monsoon, and least over the polar regions. Values are notably low for the latitude over the Sahara, where they are about the same as over Europe, but the other great desert areas are not very prominent in the run of the isopleths. Comparing the charts at different levels, it is clear that at all seasons, and over all areas on the average, half the water vapour content of the atmosphere is below $850 \mathrm{mb}$., far below the corresponding level for air at $500 \mathrm{mb}$. The highest value is over India in the summer monsoon, when the atmosphere holds 64 decigrams of precipitable water. Above the equatorial belt there is about 50 decigrams. Over the British Isles in winter the amount is about 11 decigrams and in summer 24 decigrams.

The charts permit rough calculations to be made of the ratio of precipitation to storage of water vapour in the atmosphere. Over the Earth as a whole the store is equivalent to nine days rainfall, but over wet cool regions such as the Bricish Isles in winter the average store is equivalent to only about three days rainfall. Such differences in the storage ratio reflect differences in the manner of production of rain, which is mainly by convection of 'local' water vapour over the hot regions and by advection from over the oceans in cool ones.

\section{FREEZING AND DRYING OF BIOLOGICAL MATERIALS}

$I^{N}$ recent years much has been said about the rift between science and the humanities. Nevertheless, the majority of scientists are interested in history or literature, music, drama or art, while most students of the humanities use products of science and notice the impact of others on the world at large. The widening gap between different scientific disciplines may be more serious. A stage is approaching when biologists and physicists will no longer understand one another whether they try to communicate orally or by writing. Several attempts to bridge this gap have already been made by those who investigate the effects of low temperatures and of desiccation on living cells and tissues and on their products.
The publication "Freezing and Drying of Biological Materials" is based on a conference held at the New York Academy of Sciences in October 1959*. It forms a valuable sequel to two colloquia organized by the Institute of Biology in 1951 and 1958, to the discussion at the Royal Society in 1957, and to Prof. D. Keilin's Leeuwenhoek Lecture in 1958. This is not a book for beginners. Dr. H. T. Meryman is overoptimistic in saying that a stage of simplification has been reached in cryobiology. Prof. B. Luyet is nearer the truth in thinking that the biologist who works at low temperatures is in "a chaos of disequi-

* Annals of the New York Academy of Sciences. Vol. 85, Article 2 Freezing and Drying of Biological Materials. By Harold $\mathbf{T}$. Meryman and 12 other authors. Pp. 501-734. (New York: New York Aeademy of Sciences, 1960 . 
librium and disorder". Dr. Luyet has, himself, thrown further light on the phase transition in gelatin gels and in solutions of glycerol, sugars and other biological media at low temperatures. Dr. J. L. Stephenson has continued his mathematical analysis of the process of crystallization in model biological speciInens during rapid freezing. Prof. L. Rey admits that it is almost impossible to measure the eutectic temperatures of natural substances; nevertheless, he assesses the 'eutectic requirements' of biological materials in order to reduce damage after thawing or reconstitution from the dry state. Dr. C. V. Lusena finds thet rates of formation, dissolution and redistribution of ice are very slow in solutions of glycerol below $-40^{\circ}$ C. Dr. A. C. Taylor reports that few cells from human eonjunctiva or avian skin survive rapid cooling in one stage to $-78^{\circ}$ or to $-120^{\circ} \mathrm{C}$. or when the formation of ice is sccelerated by use of hydrostatic pressure. Dr. P. Mazur thinks that when certain micro-organisms are cooled repidly in the range below $-15^{\circ} \mathrm{C}$. ice crystals in the frozen medium could seed the supercooled interior of the cells by passing through minute pores in the cell membrane ; damage, which occurs when slow thawing follows rapid cooling, might be due to migratory recrystallization of the intracellular crystals.

Contributions from authors absent from previous conferences are particularly welcome. Dr. J. Levitt describes freezing injury in plants; but his attempt to produce a single theory to explain the cause of damage in cells of animals end plants is less successful. Dr. A. P. Rinfret has studied factors affecting the erythrocyte during rapid freezing and thawing in the absence and the presence of glycerol and other protective substances. Dr. A. T. Hopkins hes used radio-frequency spectroscopy to study biological media, human erythroeytes and frog ventricles at temperatures between $0^{\circ}$ and $-100^{\circ} \mathrm{C}$. In a striking peper, Dr. H. Fernández-Morán describes tho properties of liquid helium II and its use for preparing specimens of mammalian tissue for electron microscopy. $\mathrm{He}$ elaims that his technique gives superior preservation of macro-molecular structures. Cytologists will need considerably more evidence and illustrations to convince them that freezing at $-272^{\circ} \mathrm{C}$. is necessary when subsequent staining is carried out at $-150^{\circ} \mathrm{C}$.

Dr. T. W. G. Rowe, in an excellent account of the theory and practice of freeze-drying, employs two useful terms: the 'Torr', a measure of vacuum equivalent to a pressure of $1 \mathrm{~mm}$. mercury, and the 'Lusec', the rate of leakage under a pressure difference of 1 atmosphere of 1 litre/see. at a pressure of $1 \mu$. Principles of freeze-drying are also chucidated by Dr. H. T. Meryman and Dr. R. I. N. Greaves. Dr. Greaves discusses factors involved when viability of bacteria and other living colls is to be preserved by desiccation and stresses the importance of the composition of the medium surrounding them. Dr. Meryman and Dr. E. Kafig are the first to have successfully preserved mammalian cells by freezedrying. Rat erythrocytes were intact and bull spermatozos resumed motility after drying and reconstitution under the special conditions of their experiments. It is hoped that this interesting result with bull spermatozoa will be confirmed in other laboratories.

A number of typographical errors have been noted; the figure legend on p. 523 is incorrect. Verbal efflorescences such as "organoleptic properties" (p. 527) to describe meat, "operational complementarity" and "sequentially arrested states" (p. 690) will do little to bring physicists and biologists together and would drive Mr. Thurber to his psychosemanticist. The editors are, however, to be congratulated on the speed with which they have published the report of this important conference.

AUdRey U. SMith

\title{
U.S. NATIONAL ACADEMY OF SCIENCES-NATIONAL RESEARCH COUNCIL
}

\author{
ANNUAL REPORT FOR 1958-1959
}

\begin{abstract}
$\mathrm{T}$ HE annual report for $1958-59$ of the National Academy of Sciences-National Research Council includes the review of the president, Dr. Detlev Bronk, reports on the autumn meeting, 1958, and annual meeting, 1959, of the National Academy, the Treasurer's report, list of publications and reports on the activities of the Academy and the Research Council, including those of the several Divisions, those not assigned to a Division, of the Office of International Relations, of the Office of Scientific Personnel, and of the United States National Committee for the Internetional Geophysical Year (pp. viii 224. Washington, D.C. : Government Printing Office, 1960. 70 cents). The president in his reviow stressess the increasing concern of the Academy-Research Council with international scientific activities. The new Committee on Oceanography, an outgrowth of the Intornational Geophysical Year, completed a report on the status and needs of all phases of oceano-
\end{abstract}

graphy and its opportunities, which has already stimulated greater interest in occanography and support for oceanographic research, including provision by the National Science Foundation of a new research vessel. As a result of a conference held under the auspices of the Academy and the President's Science Advisory Committee to consider how science and technology can be used more effectively by the International Co-operation Administration in its programmes of foreign assistance, the Academy was requested to study the possibilitios for such assistance to the regions of Africa south of the Sahara and north of the Union of South Africa.

During this first formative year of the National Aoromantics and Space Administration, the Space Science Board, established in June 1958, after securing programme recommendations from a broad cross-section of the scientific community, sought to develop a short-range space science programme. 